\title{
POESIA EM MÚLTIPLAS FORMAS E TONS: UMA PROPOSTA DE LETRAMENTO LITERÁRIO NO ENSINO FUNDAMENTAL
}

\author{
Joice Mariane Andrade Cruz Borba ${ }^{1}$ \\ José Jacinto dos Santos Filho²
}

\begin{abstract}
Resumo: Este trabalho tem o objetivo de apresentar uma análise preliminar sobre como se processa a tradução intersemiótica do texto literário poema para a pintura realizada pelo aluno-leitor do 6 o ano, de modo a compreender como se realiza a recepção do texto literário a partir do imaginário do aluno, observando a sua criatividade imaginativa. Serão abordadas as formas de leitura e as etapas do processo de formação do leitor. Será considerada, ainda, a relação que se estabelece entre os sinais e os signos ou linguagens. Este artigo se baseia em alguns postulados teóricos, no que se refere ao imaginário em Wunenburger (2007), à criatividade e aos processos de criação em Ostrower (2010), à semiótica em Santaella (2012), sobre leitura do texto literário, Bordini e Aguiar (1988). Desse modo, a metodologia adotada é de caráter qualitativo e o método de análise das produções dos alunos, as quais constituirão o corpus desta pesquisa, é o interpretativo.
\end{abstract}

Palavras-Chave: Poema. Pintura. Intersemiótica. Interpretação.

\section{POESÍA EN MÚLTIPLES FORMAS, EN MÚLTIPLES TONOS - UNA PROPUESTA DE LITERACIDAD LITERARIA EN EL GRUPO DEL $6^{\circ}$ AÑO DE LA ENSEÑANZA FUNDAMENTAL}

\begin{abstract}
Resumen: Este trabajo está pensado para presentar una análisis preliminar sobre cómo se procesa la traducción intersemiótica del texto literario poema para la pintura realizada por el alumno-lector del 60 año, de modo a comprender cómo se realiza la recepción del texto literario desde el imaginario del alumno, observando su creatividad imaginativa. Serán abordadas las formas de lectura y las etapas del proceso de formación del lector. Será considerada, asimismo, la relación que se establece entre las señas y los signos o lenguajes. Este artículo se basa en algunos postulados teóricos, a lo que se refiere al imaginario en Wunenburger (2007), a la creatividad y a los procesos de creación en Ostrower (2010), a la semiótica en Santaella (2012), sobre lectura del texto literario, Aguiar y Bordini (1988). De ese modo, la metodología adoptada es de carácter cualitativo y el método de análisis de las producciones de los alumnos, las cuales constituirán el corpus de esta investigación es el interpretativo.
\end{abstract}

Palabras Clave: Poema. Pintura. Intersemiótica. Interpretación.

\footnotetext{
1 Mestranda em Letras pelo PROFLetRAS na UPE/Campus Mata Norte. E-mail: joice.mariane@yahoo.com.br.

${ }^{2}$ Doutor em Educação pela UFPE. Professor Adjunto da Universidade de Pernambuco - UPE/Campus Mata Norte. E-mail: jacinto.santos@upe.br.
} 


\section{Introdução}

Este trabalho busca sistematizar uma proposta de atividade de leitura que possibilite aos alunos uma formação para o letramento literário. Para a execução desta ação pedagógica, trabalhamos com textos do gênero poema, de autoria de Mario Quintana.

Partindo da realidade vivenciada em atividades de leitura em salas de aulas de Língua Portuguesa, essa proposta de trabalho busca atenuar os desafios encontrados na formação do leitor do texto literário, com alunos do 6 으 ano, em situações didáticas de letramento.

A leitura deve, pois, vir ao encontro do atendimento dos interesses e das necessidades do leitor, representando sua maneira de ser e de ver as coisas. Nesse caso, ela "desencadeia o processo de identificação do sujeito com os elementos da realidade representada, motivando o prazer da leitura". (BORDINI; AGUIAR, 1988, p. 26).

Com o intuito de aprimorar a competência leitora dos alunos do 6으 ano do Ensino Fundamental, elaboramos uma sequência didática que pudesse contemplar práticas de tradução intersemiótica. O detalhamento das etapas que consistem nessa sequência será exposto na fundamentação teórica e na metodologia do trabalho.

A obra selecionada para a aplicação desta sequência didática é uma seleção de Regina Zilberman - Poemas para ler na escola, com textos de Mario Quintana. Essa obra traz de forma leve e imaginativa o universo da poesia em verso, abordando temas que fazem parte das vivências dos estudantes da faixa etária do 6으. ano.

\section{Leitura do texto literário}

A capacidade leitora é componente primordial à aquisição de autonomia, principalmente no que se refere aos aspectos de interação social. É a partir da apropriação dos processos de leitura e das práticas leitoras que cada indivíduo experimenta, nos vários níveis de convívio, que o ato de ler extrapola a condição de ter domínio de uma língua e perpassa por outros campos propagadores de comunicação. 
De acordo com Vera Silva (2009, p. 23-24), no que se refere à leitura, podemos distinguir pelo menos três formas de leitura, ou três atitudes do leitor durante o ato de ler. A primeira forma é a leitura mecânica, que se refere à habilidade de decodificar códigos e sinais, correspondendo ao estágio mais elementar da formação do leitor. A segunda forma é a leitura de mundo, tão difundida na proposta freiriana.

Desde muito pequenos aprendemos a entender o mundo que nos rodeia. Por isso, antes mesmo de aprender a ler e a escrever palavras e frases, já estamos "lendo", bem ou mal, o mundo que nos cerca. Mas este conhecimento que ganhamos de nossa prática não basta. Precisamos de ir além dele. Precisamos de conhecer melhor as coisas que já conhecemos e conhecer outras que ainda não conhecemos (FREIRE, 2005, p. 71).

Este modo de ler corresponde a um processo que se inicia na infância e prossegue continuamente na vida de cada pessoa; parte da decodificação inicial para os aspectos inerentes à subjetividade de quem lê e do que se lê. A terceira forma de leitura agrega a leitura mecânica e a de mundo - é a leitura crítica. Neste estágio, o leitor atinge um nível mais amplo de sua capacidade leitora, pois se torna capaz de compreender, interpretar, avaliar, criticar o que lê, elaborando suas conclusões.

Estimular o desenvolvimento da criticidade do leitor por meio do texto literário: este é o grande desafio do professor de português ao desenvolver as aulas de letramento literário. Percebe-se, portanto, a necessidade de ampliar o quanto antes o encantamento pelo texto literário, o desvendamento das nuances e o extrapolar do texto.

Este posicionamento pode ser referendado em Silva (2009, p. 29):

A trajetória de leitura deve ser iniciada o mais cedo possível, antes da alfabetização escolar, pela audição de histórias e poemas, com a criança acompanhando no livro a versão visual dada pela ilustração. Ao mencionarem o título do texto e seu autor, os grupos de contadores de histórias que se formaram nas últimas décadas demonstram sua preocupação de levar o livro ao ouvinte. Além disso, ao situarem o autor num contexto, ao contarem alguma particularidade de sua vida (a época em 
que viveu, seu país de origem) ou do personagem, eles também ajudam a despertar o interesse e a imprimir esses dados na mente do ouvinte. A bagagem cultural do jovem leitor vai, então, pouco a pouco, se enriquecendo.

O contato com obras literárias, ainda na infância, estimula o imaginário da criança e proporciona uma formação do leitor-aprendiz repleta de elementos lúdicos e significativos, que o acompanharão em toda sua trajetória enquanto leitor do texto literário. A literatura é a porta de acesso para o mundo da leitura; mundo este, repleto de possibilidades de criação e recriação dos mais variados saberes, vivências, fantasias, realidades.

De acordo com Frantz (2011, p. 17), "a escola tem falhado, e muito, na condução desse processo, no que se refere à formação do leitor. Ela não tem conseguido introduzir o aluno no mundo da leitura, a partir da beleza, da magia, do prazer, da alegria que uma boa leitura pode proporcionar ao seu leitor". Diante deste cenário, o aluno não consegue estabelecer que a leitura é uma atividade de elaboração de significados e isto pode ser recompensador em sua trajetória como leitor.

Propõe-se que a escola programe e/ou insira no planejamento das atividades escolares o desenvolvimento do hábito da leitura entre os estudantes de maneira lúdica e significativa. O professor, em especial o de Língua Portuguesa, assume o papel de mediador do diálogo que se estabelece entre texto-aluno.

Consoante Bordini e Aguiar (1988, p. 9):

Registrando a linguagem verbal, através do código escrito, o livro é um documento que conserva a expressão do conteúdo de consciência humana individual e social de modo cumulativo. Ao decifrar-lhe o texto o leitor estabelece elos com as manifestações socioculturais que lhe são distantes no tempo e no espaço.

Ao tomar consciência do sentido de um texto, o indivíduo entra em contato com o universo de quem o escreveu e adquire elementos, dos mais variados, para elaborar o seu próprio universo. A leitura tem esse poder criador e recriador. As práticas de leitura promovidas na escola são primordiais para a formação de um leitor sensível às múltiplas nuances de um texto. 
Tanto o escritor se coloca no lugar do seu leitor, quanto o leitor se coloca no lugar do autor do texto. Acontece, portanto, um processo criador que se inicia de forma individual e passa a ser coletivo, que dá "vida" ao texto, trazendo à tona seu papel social de manifestar e materializar para o mundo uma ideia. Conforme Chartier (2014, p. 144):

Nunca se lê sozinho, não se lê para si mesmo numa ilha deserta, mesmo que, durante o tempo da leitura, os leitores possam experimentar esse distanciamento do mundo que os cerca e acreditarem que estão sós com seus heróis de ficção. Mas, fechada a última página, reencontramos o mundo dos homens, e a virtude dos livros é a de mudar, pela ficção, nosso olhar sobre a realidade.

Difícil imaginar a formação de um leitor reflexivo e criativo, sem que se permita a ele um contato mais íntimo com as obras literárias. Desde sua fase inicial como pré-leitor até chegar a ser leitor competente há longo caminho para ser percorrido. Propomos que a escola seja o ambiente que estimule e potencialize as habilidades e competências necessárias para que os estudantes tenham acesso às mais variadas formas de enxergar e de descrever o mundo.

Ainda de acordo com o pensar de Aguiar e Bordini (1988, p. 13), destacamos o seguinte:

Todos os livros favorecem a descoberta de sentidos, mas são os literários que o fazem de modo mais abrangente. Enquanto os textos informativos atêm-se aos fatos particulares, a literatura dá conta da totalidade do real, pois, representando o particular, logra atingir uma significação mais ampla.

O que mais importa ao ler um texto literário não é somente a temática que ali é representada, mas, como isto é abordado no texto. Ao estimular esta competência nos estudantes, o professor estará contribuindo para a formação leitora de jovens que se tornarão capazes de estabelecer relações mais empáticas, não só entre o autor do texto, mais também, em suas interações estabelecidas em suas comunidades, escolares ou não.

A obra literária é autônoma e a formação de seu leitor carece de abordagens distintas da formação de um leitor pragmático. Sabemos que, tanto 
uma formação quanto outra, é importante para que o estudante possa exercer sua liberdade de pensamento e sua cidadania. Todavia, sugerimos que o letramento literário dos alunos seja valorizado e que as práticas de leitura não se restrinjam ao cumprimento de uma lista de obras clássicas a serem cobradas em uma prova com caráter castrador.

Observemos o dizer de Zilberman (2009, p. 32) sobre a leitura da literatura:

[...] essa atividade de decifração traduz um adentramento no real, porque o texto age como uma síntese dele. Nesse aspecto, a obra de ficção, fundada na noção de representação da realidade, exerce tal papel sintético de forma mais acabada, fazendo com que leitura e literatura constituam uma unidade que mimetiza os contatos materiais do ser humano com seu confronto físico, social e histórico, propondo-se mesmo a substituí-los.

A leitura não pragmática torna-se mecanismo de acesso ao mundo idealizado do autor e do leitor. As temáticas abordadas nos textos e a forma com que estas são desenvolvidas acabam por seduzir o jovem leitor, que passa a refletir sobre si e sobre o mundo. É incontestável a catarse que pode ser provocada, no ato de ler obras literárias, no leitor, e seus efeitos não são regidos por padrões nem podem ser delimitados.

Segundo Zilberman (2009, p. 36), a literatura desencadeia a experiência mais ampla da leitura e a sua presença no ambiente escolar ocasiona transformações profundas, extremamente necessárias; o que substancializará o processo de formação do leitor do texto literário. Processo este que, sugerimos ser iniciado nas tenras idades do estudante, com o intuito de apresentar os recursos promovedores para seu letramento literário.

\section{Literatura e imaginário}

A leitura de textos literários é tal qual um "portal" de acesso ao campo do imaginário. Como assevera Wunenburger (2007, p. 7), "fantasia, lembrança, devaneio, sonho, crença não verificável, mito, romance, ficção são várias expressões do imaginário de um homem ou de uma cultura". Por meio da 
leitura de textos literários o ser humano insere-se no universo textual do imaginário ali expresso, seja de forma verbal ou não verbal.

À medida que o leitor realiza o processo de leitura literária de forma plena, ele passa a fazer parte do mundo imaginário do texto, por conseguinte imagético, e torna-se coautor do texto. O encontro entre a mente criadora com a mente cocriadora promove um momento repleto de elaborações imagéticas, que tornam a vivência de tal leitura uma atividade de construção de significados e de deleite.

Na concepção de Wunenburger (2007, p. 10):

Conviremos, portanto, em denominar imaginário um conjunto de produções, mentais ou materializadas em obras, com base em imagens visuais (quadro, desenho, fotografia) e linguísticas (metáfora, símbolo, relato), formando conjuntos coerentes e dinâmicos, referentes a uma função simbólica no sentido de um ajuste de sentidos próprios e figurados.

Neste sentido, o imaginário instiga o leitor a construir uma ideia mais holística do texto, sem privilegiar apenas o aspecto linguístico, percebendo as variadas possibilidades de compreender e sentir o texto literário e, a partir dele, reconstruí-lo de acordo com as suas experiências prévias individuais de leitura.

De acordo com o dizer de Ricoeur (2007, p. 22), uma imagem poética é algo que transcende o próprio conteúdo literal, por apresentar uma composição carregada de pluralidade e inúmeros significados. No ato da elaboração de uma imagem poética, o eu do leitor extrapola o signo linguístico e permeia espaços ilimitados do texto que em cada nova imersão se ampliam, se propagam e se reelaboram.

Sobre as formas de abordagem, nem todos os imaginários apresentam-se atrelados aos mesmos suportes; eles compreendem aspectos linguísticos, como também expressões visuais, formando um tipo de textura verbo-icônica cujas características não se unificam devido à heterogeneidade dos dois registros.

Conforme Wunenburger (2007, p. 28): 
Com efeito, a função linguística abrange uma entidade específica de imagem cujas equivalências estruturais ou funcionais com a imagem visual são fonte de problemas. A experiência escópica do olho, que nos fornece representações analógicas dos objetos, e a experiência da verbalização, ligada inicialmente à voz, que substitui o real pelos signos convencionais e abstratos da língua, de fato constituem duas fontes e registros claramente diferenciados de informação e de expressão do homem.

Os padrões de estudo do imaginário foram lapidados em vários campos do conhecimento (como a crítica literária, antropologia, psicanálise, filosofia, ciências religiosas etc.). A maioria desses padrões mistura muitos tipos de abordagem, que alternam entre dois pontos: a semiótica estrutural e a hermenêutica simbólica.

A semiótica estrutural compreende o imaginário literário como determinado pelos signos linguísticos, devido às suas propriedades combinatórias e expressivas. Na hermenêutica simbólica, a prática da interpretação compreensiva do imaginário foi aplicada primeiramente aos textos mítico-religiosos, cujo sentido imagético se apresenta sempre equívoco, percebendo-se uma dualidade que se estabelece entre sentido literal e figurado; em que o nível literal deixa de ser a expressão da verdade pura e passa a ocupar um nível de superficialidade que abriga em seu interior a amplitude do sentido a ser construído.

O imaginário pode ser apreendido de forma organizada, mediante métodos que interliguem as partes de um todo, oriundo de processos humanos inconscientes. Não confundamos aqui, o termo inconsciente com o termo irracional; haja vista tais processos ocorrerem em um tempo-espaço diferente; porém, inseridos num contexto que possui significação para o ser humano.

Como afirma Ostrower (2010, p. 10), "O homem cria, não apenas porque quer, ou porque gosta, e sim porque precisa; ele só pode crescer enquanto ser humano, coerentemente, ordenando, dando forma, criando.". A espécie humana é culturalmente impelida à criação, porque esta faculdade encontra-se fecundada em sua essência, evidenciada pela intuição.

Por meio da intuição, o ser humano toma decisões que satisfazem as necessidades que a vida lhe impõe. Logo, o processo de criação perpassa pela 
intuição e ao tomar consciência deste processo o homem dá uma forma, expressando-se em seu contexto social; tomando consciência, também, de si mesmo no desenvolvimento de sua criatividade.

Partindo desta premissa, entendemos que toda ação humana apresenta intencionalidade, uma vez que o ser humano se mobiliza interiormente para adequar-se à situação concreta. A imaginação é associada à circunstância vivenciada e este consegue solucionar o problema e/ou desafio experimentado. $\mathrm{O}$ ato de criar está inserto na intencionalidade, pois o indivíduo estabeleceu critérios para escolher o jeito mais adequado de solucionar determinada ocorrência.

O homem é um ser simbólico em sua essência, conseguindo nomear, identificar e generalizar as coisas que compõem seu contexto, seu ambiente. É capaz de simbolizar objetos e ideias estabelecendo relações; consegue perceber a unidade em meio à multiplicidade e vice-versa. Esta competência permite que ele possa se colocar no lugar do outro imaginativamente e estabelecer um distanciamento sobre seu próprio eu, ampliando o entendimento que pode ter sobre si mesmo.

No centro do ato criativo, o ser humano exerce sua capacidade de comunicar-se por meio de formas. Isto porque toda produção humana, verbal ou não verbal, é realizada de maneira ordenada para atender a uma intencionalidade que, por sua vez, está atrelada a uma necessidade de adequação contextual.

A leitura de um texto literário é um momento de encontro de um imaginário com outro imaginário. Não há controle e/ou delimitação das possibilidades de interpretação que podem acontecer nesta atividade mental. O processo de letramento literário é um percurso coletivo e também individual; a subjetividade do autor e do leitor constituirão a produção de uma outra subjetividade, a obra literária adquire nova roupagem.

Vejamos o que diz Petit sobre os jovens e a prática da leitura:

Compreendemos que por meio da leitura, mesmo que esporádica, podem estar mais preparados para resistir aos processos de marginalização. Compreendemos que ela os ajuda a se construir, a imaginar outras possibilidades, a sonhar. A encontrar um sentido. A encontrar mobilidade 
no tabuleiro social. A encontrar a distância que dá sentido ao humor. E a pensar, nesses tempos em que o pensamento se faz raro (PETIT, 2008, p. 19).

Quando Petit diz que a leitura se torna um mecanismo de defesa contra a marginalização, remetemo-nos à proposta Freiriana que propaga autonomia do indivíduo por meio de seu letramento. A leitura de mundo depende também do desenvolvimento da capacidade imaginativa e de senso crítico; elementos importantes para que cada jovem, cada estudante, possa vislumbrar horizontes mais largos, mais promissores.

O imaginário, este espaço etéreo, abundante em possibilidades permite ao homem ser mais humanizado. É a partir das experiências que a mente humana vivencia neste campo que a realidade se transmuta, tornandose mais palpável e perceptível aos olhos a ação do ser humano no ciclo vital de produção, de (re)criação.

\section{Literatura e semiótica}

A semiótica é uma ciência que estuda os signos em geral. O termo semiótica vem da palavra grega semeion, que quer dizer sinal, marca, signo. A busca pelo entendimento dos problemas da linguagem começou no mundo grego e, no século XX, a semiótica ficou conhecida como uma ciência.

Partindo desse pressuposto, a semiótica é uma ciência que desenvolve estudos sobre todas as formas de linguagem.

Consoante Santaella (1992, p. 13), “a semiótica é a ciência que tem por objeto de investigação todas as linguagens possíveis, ou seja, que tem por objetivo o exame dos modos de constituição de todo e qualquer fenômeno como fenômeno de produção de significação". Com base neste entendimento, compreendemos que toda produção comunicativa do homem estabelecerá um ponto de elaboração de elementos de linguagem e, com isso, a produção de signos que efetivam o processo de criação e recriação de significados.

O signo corresponde a qualquer coisa que venha a representar uma outra coisa, ele representa algo que não é o próprio, ou seja, o objeto do signo; produzindo um efeito interpretativo em uma mente real ou potencial; este efeito é denominado de interpretante do signo. 
Logo, compreendemos a existência de uma tríade: signo, objeto e interpretante. Os dois primeiros elementos podem ser qualquer coisa de qualquer espécie. O que vai determinar a distinção de cada um dos três elementos é a posição lógica que cada um ocupa no processo de representação.

Santaella (2012, p. 4) esclarece que:

As diversas facetas que a análise semiótica apresenta podem assim nos levar a compreender qual é a natureza e quais são os poderes de referência dos signos, que informação transmitem, como eles se estruturam em sistemas, como funcionam, como são emitidos, produzidos, utilizados e que tipos de efeitos são capazes de provocar no receptor.

A análise semiótica nos permite compreender o processo existente de signos, sejam eles verbais, não verbais ou naturais. Trata dos mecanismos de construção dos modos de significação e seus desdobramentos nas etapas de compreensão e interpretação de uma informação.

Em Santaella (2012, p.5), a definição de signo, elaborada por Peirce, tem uma base tríplice, podendo este ser analisado em si mesmo (poder de significação), na sua referência àquilo que indica (poder de representação) e nos tipos de efeitos que apto a produzir nos seus receptores (poder de possibilitar múltiplas interpretações) (grifo da autora).

A teoria semiótica nos propicia um desvendamento de como as mensagens se organizam internamente e as possíveis repercussões que estas podem ocasionar em seus interlocutores, de acordo com seus referenciais pessoais, históricos, culturais; isto é, de acordo com o contexto em que os interlocutores estão inseridos. Observando também as naturezas distintas que as mensagens podem apresentar como a verbal, a imagética, a sonora e suas combinações.

Contudo, não devemos ter a intenção de, por meio da análise semiótica, traçar um único percurso para a compreensão de como as mensagens podem ser articuladas e compreendidas. A semiótica delineia aspectos importantes para que a análise possa acontecer de forma coerente, sem menosprezar outros conhecimentos mais específicos da história de um determinado processo de signos. 


\section{Metodologia}

Este trabalho, fruto de nossos estudos no PROFLETRAS, foi desenvolvido em uma escola da Rede Pública Estadual, com alunos do 6ㅇ ano do Ensino Fundamental. A proposta de atividade para o letramento literário se fundamentou na aplicação de sequência didática, articulando o texto literário poema com a linguagem imagética da pintura.

Vejamos a ideia de Dolz e Schneuwly $(2004$, p. 43) sobre o trabalho com sequência didática:

As sequências didáticas instauram uma primeira relação entre um projeto de apropriação de uma prática de linguagem e os instrumentos que facilitam essa apropriação. Desse ponto de vista, elas buscam confrontar os alunos com práticas de linguagem historicamente construídas, os gêneros textuais, para lhes dar a possibilidade de reconstruí-las e delas se apropriarem.

Percebemos, a partir deste posicionamento, que a utilização de sequência didática no desenvolvimento de um projeto envolve o emprego de mecanismos que estimulam os alunos a defrontar os conhecimentos já elaborados com os que poderão ser reelaborados, mediante práticas de linguagem.

A seguir, apresentamos uma proposta de Sequência Didática de trabalho com tradução intersemiótica, para execução em sala de aula.

\section{Etapa 1: Atividade Preparatória:}

Para executar a primeira etapa desta sequência didática, recomendamos que o professor defina o gênero textual a ser trabalhado e a linguagem artística (pintura, fotografia, cinema, música, teatro) que será utilizada na tradução intersemiótica.

O professor apresenta o gênero textual escolhido, neste caso, o poema, por meio de leitura-deleite de um texto. Os textos utilizados nesta proposta são da obra “Poemas para se ler na escola - Mário Quintana”, seleção Regina Zilberman. Este é o momento de permitir que o aluno-leitor comente o 
texto, exponha suas impressões e sensações sobre a leitura feita, seja pelo professor ou por um aluno.

Em seguida, o professor apresenta a linguagem artística que se relacionará com o gênero textual escolhido. Nesta proposta, a pintura será a linguagem utilizada para o trabalho intersemiótico. O professor mostra aos alunos-leitores os textos imagéticos que estabelecem algum tipo de relação intertextual com os poemas lidos na sala de aula. Recomendamos esclarecer aos alunos sobre a distinção entre ilustração e tradução.

Na atividade preparatória, sugerimos que a validação da participação do aluno-leitor seja realizada de maneira oralizada; de modo breve, para que todos tenham a oportunidade de se expressar. Sugerimos o período de 2(duas) aulas para a execução desta etapa.

\section{Etapa 2: Produção Inicial:}

A segunda etapa desta sequência didática consiste na primeira produção do aluno. Como este trabalho estrutura-se na tradução intersemiótica de poema para a pintura, indicamos a produção pictórica.

O professor solicita aos alunos que produzam o texto imagético, deixando-os livres para escolher o tema, cores e formas que comporão a pintura, e orienta-os que se permitam imaginar, visitar memórias, elaborar uma mensagem por meio da arte plástica.

Para esta etapa da sequência, sugerimos que o professor utilize 2(duas) aulas, preferencialmente aulas geminadas; com o intuito de não haver uma ruptura temporal na produção pictórica.

\section{Etapa 3: Oficina de Leitura:}

Já que esta proposta interventiva busca a formação do leitor do texto literário, em turma de 6ำ ano do Ensino Fundamental; indicamos que, após a produção inicial, os alunos-leitores participem de uma oficina de leitura, com a duração de 2(duas) aulas.

Nesta oficina, o professor trabalhará com os alunos os textos que forem previamente selecionados - Canção da primavera e Canção de garoa, de 
Mario Quintana,1946 - e coordenará as mudanças de turno entre leitura e comentário sobre o poema lido.

Para validar a participação do aluno-leitor, propomos que o professor solicite aos estudantes que escrevam um pequeno comentário a respeito do poema que mais lhe tocou; transpondo para a escrita a expressão de seu eu ao entrar em contato com o texto.

\section{Etapa 4: Oficina Artística:}

A pintura será a linguagem artística para a execução desta oficina. Recomendamos que o professor se aproprie dos elementos básicos (exemplo do pictórico: linha, cor, valor, contorno, forma, espaço, textura, equilíbrio, contraste, ênfase, ritmo, unidade e proporção) que caracterizam a linguagem artística escolhida.

Nesta etapa, os alunos terão acesso às técnicas elementares de pintura para que possam produzir o texto imagético em tela. Sendo assim, sugerimos que o tempo de 1(uma) aula seja direcionado para a exposição das técnicas e 1(uma) aula para a produção pictórica individual.

\section{Etapa 5: Produção de Tradução Intersemiótica:}

Nesta etapa da sequência, o professor selecionará um poema que será traduzido para a pintura. Para esta atividade interventiva, selecionamos o poema Canção de nuvem e vento, de Mario Quintana (1946).

O professor faz a leitura oralizada do poema para os alunos e solicita que eles expressem por meio da pintura as emoções, as impressões que tiveram no momento da escuta do poema.

É importante que o professor esteja atento às observações que os alunos fizerem, para que não tendam a ilustrar o poema, mas sim traduzi-lo para a pintura.

Esta atividade de produção pictórica corresponde ao estágio principal para se atingir o objetivo geral desta proposta, pois demonstrará a capacidade do leitor acessar os campos subjetivos de uma obra literária. 
Propomos o tempo de 2 (duas) aulas para a realização desta etapa da sequência didática.

\section{Etapa 6: Validação da Produção:}

Tendo em vista que este trabalho possui abordagem de pesquisa participante, nesta etapa de execução sugerimos que haja a validação das produções efetuadas pelos alunos-leitores com a partilha dos saberes entre a comunidade escolar.

Dependendo da linguagem artística que for escolhida, podemos propor a publicação de livro, exposição (pintura, fotográfica), apresentação musical, mostra de cinema, dramatização, sarau. Mediante a proposta de utilizar a pintura como elemento de materialização das imagens poéticas, validaremos as produções dos estudantes por meio de um livro, contendo as imagens das pinturas e o comentário de cada aluno-autor a respeito de sua obra.

Nesta última etapa, o professor definirá o tempo de acordo com a estratégia de validação mais adequada à linguagem artística que for escolhida para o desenvolvimento da proposta interventiva. Como o produto final deste trabalho interventivo será a publicação do livro, destinaremos o tempo de 5 (cinco) aulas para realização da exposição das produções; de maneira que a comunidade escolar possa apreciar o trabalho e ter contato com os alunosautores.

\section{Análise do corpus}

A análise preliminar das produções dos alunos foi mediante os dados coletados nas Etapas 2, 3 e 4 desta sequência didática. Selecionamos as produções de três participantes das oficinas e utilizamos, para identificá-los, a sigla P1 (para participante 1), P2 (para participante 2) e P3 (para participante 3).

Nas produções da Etapa 2, os alunos produziram um texto imagético, usando papel sulfite e lápis coloridos. Não houve utilização do texto verbal (poema) ou imagético como referencial para esta etapa. Com o intuito de estimular no aluno o acesso ao seu imaginário e/ou lembranças de vivências 
por eles experimentadas, um questionamento foi lançado: Qual sentimento você quer expressar hoje?

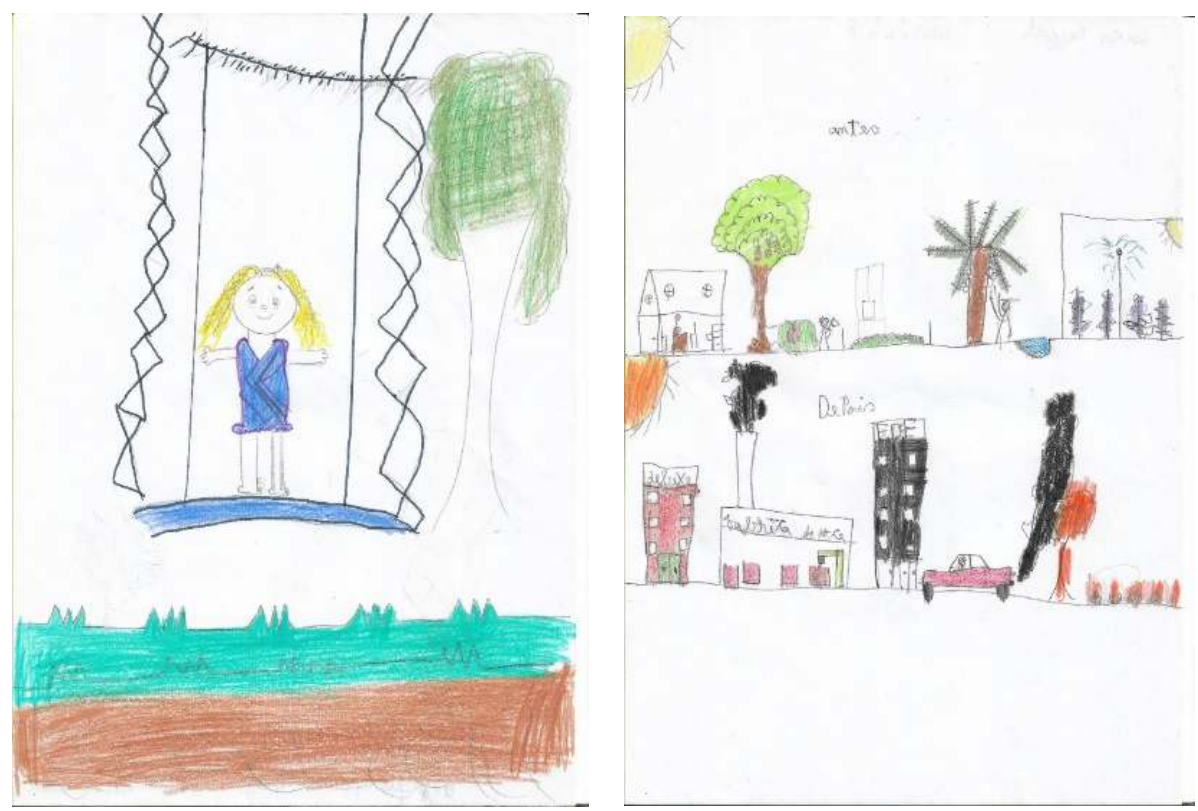

Texto imagético (lápis de cor sobre papel) - P1 Texto imagético (lápis de cor sobre papel) - P2

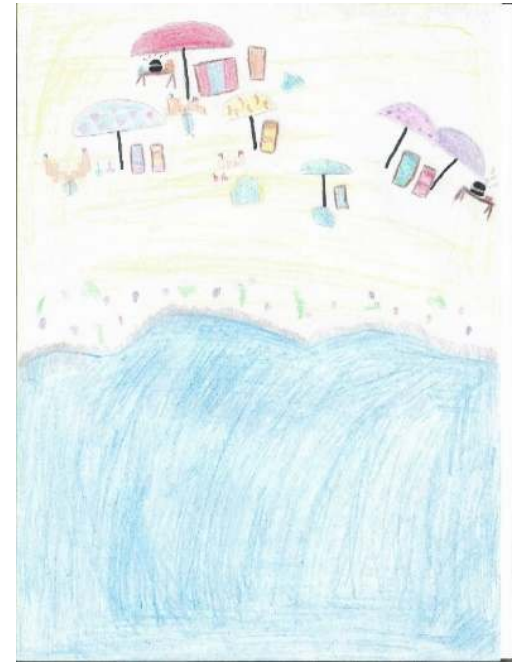

Texto imagético (lápis de cor sobre papel) - P3 
POESIA EM MÚLTIPLAS FORMAS E TONS:

UMA PROPOSTA DE LETRAMENTO LITERÁRIO NO ENSINO

Nestas três produções podemos perceber o destaque dado às influências do meio sobre os participantes. No texto do P1, observamos a conexão com a ambientação natural, revelando um lazer comum às pessoas desta faixa etária e a satisfação que isto pode trazer, sendo revelado pela expressão da menina no balanço. No texto do P2, notamos a preocupação com relação à ação humana sobre o ambiente natural, ao retratar um espaço urbanizado e os efeitos negativos deste processo, destacados com o uso da cor preta, indicando poluição ambiental. No texto do P3, percebemos um aspecto harmônico do ambiente retratado, tendo em vista o uso de tons mais suaves e traços equilibrados.

Nas produções da Etapa 3, os alunos escreveram um breve comentário sobre os textos de Mario Quintana, que foram lidos em sala com eles.

Texto verbal $-\mathrm{P} 1$

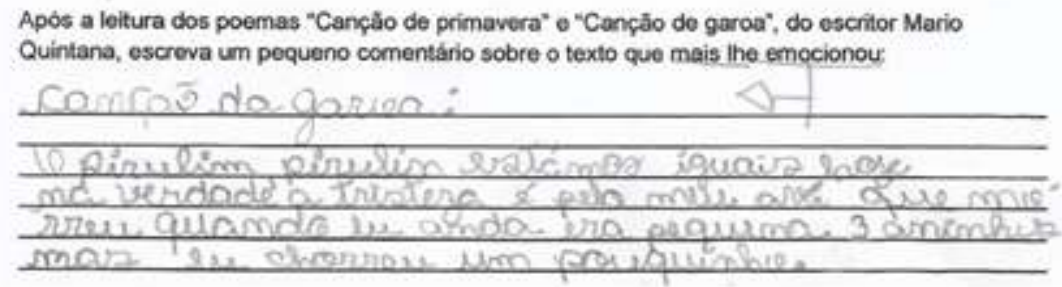

Texto verbal $-\mathrm{P} 2$

Após a leitura dos poemas "Cançăo de primavera" e "Cançło de garoa", do escritor Mario Quintana, escreva um pequeno comentairio sobre o texto que mais the emocionou.

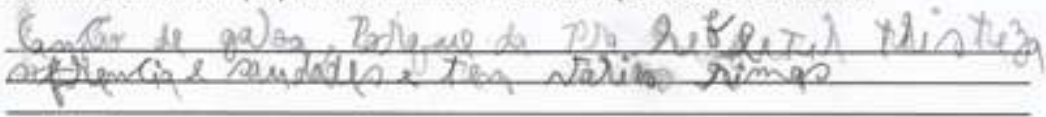

Texto verbal $-\mathrm{P} 3$

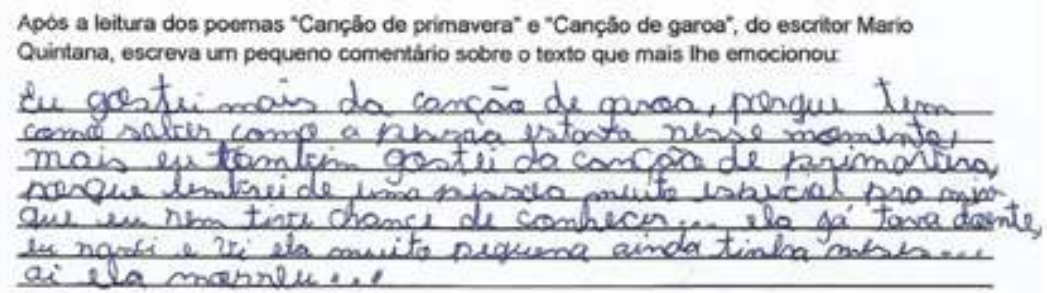

Pontos de Interrogaçầo, v. 10, n. 1, jan.-jun., p. 193-213, 2020. 
Nos três comentários produzidos pelos participantes, verificamos que o poema Canção de garoa foi o que mais os emocionou. P1 e P3 revelam ter se lembrado de um ente querido ao ler o texto e a saudade é um elemento forte; a temática da morte é acessada ao ler o poema que cita a ação dos pingos da chuva e esta representação da chuva fez com que os alunos associassem às lágrimas. A expressão do eu lírico do autor inspirou o eu do leitor a reviver certas emoções dos afetos que se foram. Para P2, a saudade foi o sentimento mais forte; o elemento estético do poema - a rima - foi um ponto de destaque para P2. A função catártica do texto literário, nesta produção textual, é percebida de modo evidente, pois, ao ouvir a leitura do poema, os participantes relembraram momentos significativos em suas vidas e se emocionaram.

Nas produções da Etapa 4, os alunos participantes eleboraram um texto pictórico como evidência na participação da oficina artística.

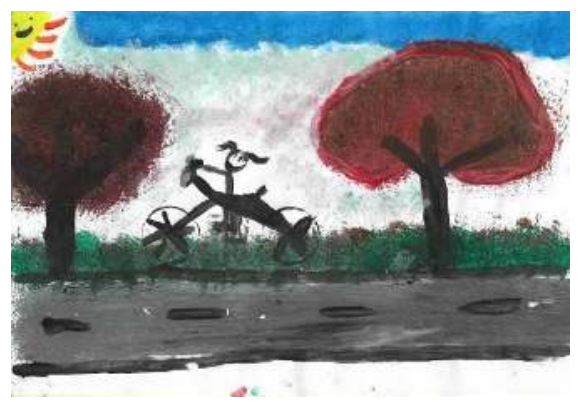

Texto imagético (guache sobre papel) - P1

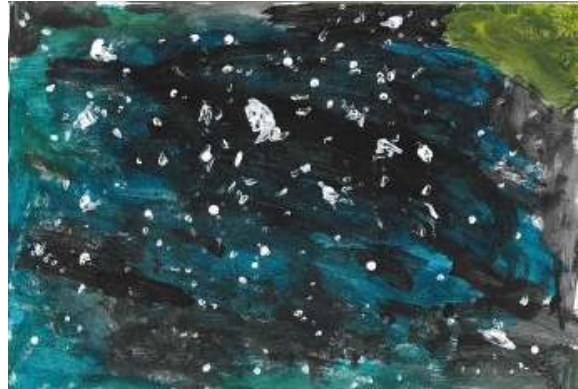

Texto imagético (guache sobre papel) - P2

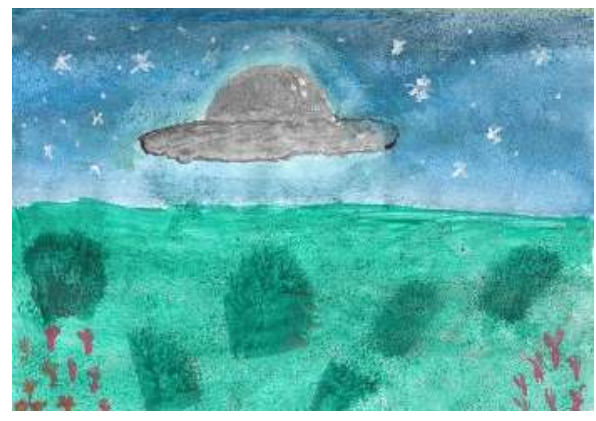

Texto imagético (guache sobre papel) - P3 
Nas produções acima, os alunos participantes permitiram que seu imaginário estivesse em fruição. P1 expressou sua imaginação retratando um passeio de bicicleta, P2 retratou a Via Láctea e P3 retratou a lua por trás das nuvens em noite estrelada. Um ponto em comum é que nas três produções o cenário envolvendo elementos que compõem a natureza estão em evidência as árvores, a galáxia e o céu noturno. Portanto, podemos entender que o processo de produção do texto imagético favoreceu a reflexão sobre o ser humano e sua relação com a natureza. A Literatura tem esse poder de permear o íntimo do leitor e fazer desabrochar emoções no ato de ler. Percebemos a função hedonística do texto literário sendo expressa nas produções pictóricas dos participantes, tendo em vista que os três demonstraram um estado contemplativo do meio ambiente e a interação entre os indivíduos.

\section{Considerações finais}

Tendo em vista o que foi apresentado na fundamentação teórica deste trabalho de pesquisa, que consistiu nas formas de leitura e as etapas do processo de formação do leitor, na relação que se estabelece entre os sinais e os signos ou linguagens, no imaginário, na criatividade e nos processos de criação, na semiótica; bem como nas experiências de letramento literário desenvolvidas em sala de aula; entendemos, portanto, que o processo de tradução intersemiótica que se estabelece entre a linguagem verbal (por meio da leitura de poema) e a linguagem pictórica (por meio de pintura) envolve aspectos ligados ao nível de maturidade do letramento literário dos alunosleitores.

Quanto mais os alunos estiverem habituados às práticas de leituras literárias, mais eles poderão mergulhar no imaginário e liberar seu potencial criativo nas traduções intersemióticas por eles realizadas. A semiótica nos traz elementos de reflexão sobre os efeitos que o signo pode proporcionar na mente do leitor e as repercussões ocorridas nos processos de criação, co-criação e recriação textual.

Ao aplicar a sequência didática, notamos que a utilização do texto literário poema, "Canção da primavera" e "Canção de garoa", de autoria de Mario Quintana, influenciou de modo significativo na relação existente entre 
texto-leitor-texto. De modo que o lirismo empregado nos textos trabalhados em sala foi elemento importante, para que os alunos entrassem em contato com o imaginário do autor e pudessem encontrar a si mesmos no texto selecionado.

Observamos nas produções pictóricas que os alunos não se limitaram em apenas ilustrar o texto abordado; eles conseguiram traduzir, por meio da linguagem imagética, o sentimento experimentado no momento da leitura dos poemas, que os fizeram perceber as nuances do lirismo presente nos textos trabalhados em sala de aula.

Sendo assim, após a aplicação da sequência didática e da análise preliminar do corpus deste trabalho de pesquisa, constatamos que os efeitos da leitura do texto literário podem ser representados tanto pela linguagem verbal quanto pela linguagem pictórica, pois antes do poema se materializar em texto verbal, ele foi sentido e pensado enquanto imagem mental.

\section{Referências}

BORDINI, Maria da Glória; AGUIAR, Vera Teixeira de. Literatura:a formação do leitor: alternativas metodológicas. Porto Alegre: Mercado Aberto, 1988.

CHARTIER, Anne-Marie in: PAIVA, Aparecida; MARTINS, Aracy; PAULINO, Graça; VERSIANI, Vera (Org.). Leituras literárias: discursos transitivos. 2. ed. 1. reimp. Belo Horizonte: Ceale; Autêntica Editora, 2014.

FRANTZ, Maria Helena Zancan. A literatura nas séries iniciais. Petrópolis, RJ: Vozes, 2011.

FREIRE, Paulo. A importância do ato de ler: em três artigos que se completam. 46. ed. São Paulo: Cortez, 2005.

OSTROWER, Fayga. Criatividade e processos de criação. 25. ed. Petrópolis, Vozes, 2010.

PETIT, Michèle. Os jovens e a leitura: uma nova perspectiva. Tradução de Celina Olga de Souza. São Paulo: Editora 34, 2008.

QUINTANA, Mario. Poemas para ler na escola. Seleção e apresentação Regina Zilberman. Rio de Janeiro: Objetiva, 2012. 
RICOEUR, Paul in: WUNENBURGER, Jean-Jacques. O imaginário. Tradução de Maria Stela Gonçalves. São Paulo: Edições Loyola, 2007.

SANTAELlA, Lúcia. $O$ que é semiótica. 10. ed. São Paulo: Editora Brasiliense,1992.

Semiótica Aplicada. São Paulo: Cengage Learning, 2012.

SILVA, Vera Maria Tietzmann. Leitura literária \& outras leituras - impasses e alternativas no trabalho do professor. Belo Horizonte: RHJ, 2009.

SCHNEUWLY, Bernard; DOLZ, Joaquim e colaboradores. Tradução e organização: ROJO, Roxane; CORDEIRO, Glaís Sales. Gêneros orais e escritos na escola. Campinas, SP: Mercado das Letras, 2004.

WUNENBURGER, Jean-Jacques. $O$ imaginário. Tradução de Maria Stela Gonçalves. São Paulo: Edições Loyola, 2007.

ZILBERMAN, Regina in:ZILBERMAN, Regina; RÖSING, Tania M. K. orgs. Escola e leitura:velha crise, novas alternativas. São Paulo: Global, 2009.

Recebido em 29 de abril de 2020.

Aceito em 20 de junho de 2020. 